\title{
Relative Rating Versus Cost of Living as a Basis of Adjusting Wage-Rates
}

\author{
By Thomas W. Mitchell, Ph.D. \\ Management Engineer
}

$\mathrm{T}$ HE period that commenced seven years ago and is not yet finished has been a period of test for our ideas and institutions, political and industrial. Particularly has it furnished opportunity for applying, testing, reviewing and revising some of our economic notions.

The World War drew out of industry and put into the military organization between three and four millions of our own young men, not to mention the millions of Europeans. It transferred other hundreds of thousands from ordinary industry to the production of munitions and other war materials. All these had still to be fed, clothed, amused and the like, although they had ceased to produce, either directly or indirectly, their own sustenance. It should have required but a moment's thought to convince us that, unless these millions were replaced by other producers (by women, say) or unless those who remained in ordinary industry were considerably more effective than before, the whole population would have to live in poorer circumstances than prior to the outbreak of the War.

However it soon became apparent that the mass of workers, whether in factories or offices, did not comprehend the situation in this manner. Not only did a large part of the working population go shopping for jobs at higher pecuniary rates and keep up this shopping practice until the day of the Armistice-as if it were money they ate and wore and slept in-but when the inevitable price advances came to increase the pecuniary cost of living, they demanded the privilege of living as well as they had been accustomed and demanded still higher wage- and salary-rates, which were followed by yet higher prices and living costs. Governmental wage adjustment boards raised the wage-rates of shipyard workers and others to cover the advance in living costs, only to find in a short time that further price increases had absorbed the pecuniary wage increases, so that they had the job to do over again. Finally, one board came to the conclusion that mere wage-rate increases only added to the cost of living, that no given standard could be maintained by that method, and ceased the practice.

Several years before the World War at least one collective bargaining agreement specifically recognized changes in living costs as an important consideration in adjusting wage-rates up or down. During the post-war period of rising prices, arbitrators in a number of cases granted general wagerate increases on the basis of advances in living costs. Other demands have been made on that basis, although not granted. In one case the arbitrator stated that workers were entitled not only to rate increases commensurate with the advance in the cost of living, but, as time went on, to still further rate increases for the purpose of improving their living conditions. Many representative economists, industrial engineers and other thoughtful persons, also put large faith in the living cost theory.

Now, however, that prices are on the downward swing, while many groups 
of workers accept rate-cuts with apparent cheerfulness, there are other large groups who resist such reductions even to the extent of prolonged strikes. There are employers, too, who are following the cost of living theory out to its logical conclusion and are asking such intimate questions as these: What is the average size of workers' families? How many pairs of shoes, of stockings, how many suits of underwear, of outer garments, how many ounces of beef, potatoes, bread, butter and the like; how much bedroom and other room space, does each member of the family need, and what is the cost of these per week or per annum? When employers commence seriously to ask such questions for the purpose of cutting wage-rates, is it strange that workers and their representatives become uneasy and begin to wonder whether after all the living cost theory is a logical and beneficent one?

The present situation furnishes the opportunity to reëxamine the living cost theory, to ask ourselves what the function of a standard of living is, through what channel it accomplishes its purpose and, more particularly, whether it is logical and effective as a basis of pecuniary rate adjustments.

\section{Living Standards Have Round-}

\section{About not Direct EFfect}

Anyone who will take the trouble to review the development of economic thought on the subject or thoughtfully examine the facts of industrial operation, must become convinced that the function of standards of living is to control the proportion of population and the labor factor to the other factors in production.

In the production of any commodity or the performance of any operation the various production factors-land or space factors, equipment factors, labor factors and planning and super- vision factors-may be combined in any one of a range of proportions. To each combination there will correspond a rate of output that differs from that of every other combination. Advance in scientific knowledge, which makes possible a more effective application of scientific laws, may increase the rate of output of each possible combination. However it can be shown that without such advance in scientific knowledge and improvement in the industrial arts, there are two sets of proportions at the opposite extremes of a range such that for any set of proportions within the range, if the proportion of any one factor to the others be increased, the total rate of output of the whole combination will be increased, it is true, but less than proportionately to the augmentation of the one factor. In other words, increasing the proportion of one factor in the combination within this range subjects the other factors to the operation of a "law of diminishing returns," or the one factor to a "law of diminishing productivity."

Now the total quantities of equipment factors are capable of being increased and are increased as industrial society saves. Likewise, the human factors increase as the population increases. However the increase of the land factor is obviously limited by the fact that the total land area of the world is practically a fixed quantity. The bearing of this upon the welfare of mankind is obvious. If the population increases more rapidly than does the accumulation of the equipment factors, particularly if it increases more rapidly than the advance of scientific knowledge and the effectiveness of the industrial arts, the average rate of production of commodities per person or per man-hour must fall, and the economic well-being of the human factors-and industry is carried on for 
the benefit of the human factorsmust be lowered. Indeed, barring the progress of science, there is a maximum beyond which the output of the whole industrial society of the world cannot be increased; to increase the proportion of the human and equipment factors beyond this limit is to decrease the total output of commodities.

If, therefore, the economic well-being of the mass of people is not to be lowered, it will be necessary to prevent the population and the human factors from increasing more rapidly than the accumulation of the equipment factors and, more particularly, to prevent this increase from outrunning the advance of scientific discovery and invention and the improvement of the industrial arts.

But how are we to prevent the population from increasing so rapidly? Each person will have to do his little part by deferring marriage and limiting his contribution to the increase of population. As one labor manager remarked concerning the "make-work theory" that is said to pervade the ranks of industrial workers, "If workpeople are going tolimit out put, the output to limit is the output of children."

But when shall a person marry and how many children shall he bring into the world? Here comes in the function of a personal standard of living. The more kinds and degrees of his own wants a person puts ahead of his desire for his own home and family, the more kinds and degrees of wants of a potential spouse and each potential child he puts ahead of his desire for a larger family, the longer he will defer his marriage and the smaller will be his personal contribution to the increase of population. From his personal viewpoint he will take more time to acquire skill and industrial effectiveness, to advance to grades of work of higher skill and value, until he can command an income, and be reasonably sure of maintaining it, that is sufficient to enable him to support himself, wife and prospective children according to the standard he has chosen. The more people adopt high living standards, conduct themselves accordingly and so limit each his personal contribution to the population, the slower will be its increase and the more chance will the progress of science and the industrial arts have to keep pace with and even outrun the increase in population. Indeed it is possible to hold the population stationary, as in France, or actually to decrease it. If a sufficient portion of the population adopts relatively high standards of living and conducts its marital practice accordingly, within limits, any standard of living can actually be attained and maintained.

Observe, however, that it is not sufficient, at a given set of market prices of commodities, to say, "Go to! I want to live on a scale requiring an income of $\$ 5,000$ a year and insist on having $\$ 5,000$ a year instead of $\$ 2,000$." That might be effective for one person or a comparative few so long as the mass of people were not doing the same thing; but if the mass of people should attempt to do the same thing, even though they might actually get the larger money income, as happened all over the world during the last seven years, so long as they did not increase their volume of production correspondingly, the only effect would be to mark up the prices of commodities in like proportion. Wage boards can better the living conditions of selected groups of workers for a little while by marking up their pecuniary wage-rates, provided that other wage boards or agencies do not simultaneously mark up the wage-rates of the remainder of the working population. In other words, so long as they do not increase the 
productivity of industry, all that wage boards, arbitrators and labor unions can accomplish by marking up wage-rates is to alter the division of the total product of industry among the various groups of workers. However the improved living conditions of the few come at the expense of the others.

To sum up, raising the standards of living produces its effects only indirectly: (1) by causing the individual to put forth the improving effort and take the time necessary to increase his own productivity; (2) by restraining the growth of population, thereby keeping down the proportion of labor force to the other factors, particularly to land. Its effect is a long run and round-about, not an immediate and direct effect. Neither wage boards nor legislative nor collective bargaining fiat can accomplish it.

Furthermore, a standard of living is not something that can be chosen by one person or by a wage board for another person. I can choose my own standard of living and $I$ can accustom my children to it so as to be reasonably sure of passing it on; but I cannot effectively impose any given standard of living on any person outside my family. For even though I place the corresponding income at the other person's command, unless he has already chosen that standard for himself, I cannot compel him to keep his family so small as to make the standard effective. A standard of living is a personal affair. Each person must, consciously or unconsciously, choose his own. There is not one standard of living; there are millions.

\section{General Wage-Rate Changes Im- potent to Affect Economic Well-Being}

This thought that wage boards, arbitrators and labor unions are powerless to better or to injure the economic well-being of the masses of workpeople by mere general increases or decreases of wage-rates, that they can only discriminate in favor of or against one group of workers as compared with the other groups, is so important as to merit further demonstration.

It is possible to benefit or to injure tool makers or glass-blowers or locomotive engineers or clothing workers or any other group of workers or even a number of such groups in this manner so long as the movement is not general. However, any attempt to make a general and universal proportionate advance or recession in wage- and salary-rates immediately defeats its purpose. For, unless such advance or recession is connected with, and accompanied by, an increase or decrease in the rates of production of commodities, it will immediately be followed or accompanied by a like proportionate general advance or recession in the prices of commodities, so that the general advance or recession in wage and salary incomes will be wholly absorbed in a proportionate advance or recession in the money-cost of living. The pressure of the real cost of living will be unabated.

Economic relationships and the operation of fundamental economic forces are obscured by the form and mechanism of our present industrial organization-by the fact that no one person himself produces more than a small part of what he himself uses; by the fact that he works as a small part of an industrial unit and does only a small part of the total work involved in producing the product that his unit produces; by the fact that he does not receive as his share of the product of his unit, a part of that product, but receives, instead, money; by the fact that exchange is not made directly of product for product, or of labor for product, but that, on the contrary, the 
worker exchanges his labor for money, his employer takes the product and exchanges it for money, and all the people who receive money incomes exchange the money for the products they want. The fact that all our exchange is thus indirect; that there is, and must be, a medium of exchange, money,--necessary though this is in our modern industrial organization which is based on the principle of the division of labor-obscures the real purposes of industry and the working of economic laws.

However, if we look through this external mechanism to the underlying purposes and forces, we shall see that it is impossible to improve or lower the well-being of the whole mass of industrial workers by merely increasing or decreasing their money incomes. The only way to effect either is to increase or decrease, in all or nearly all lines of production, the total volume of product. No matter how much money is paid to the masses of the people, with it they cannot buy bread that does not exist; they cannot buy shoes that do not exist; they cannot buy clothes that do not exist; they cannot buy any of the necessities, comforts and luxuries of life that do not exist. And these things exist and are available for purchase only to the extent that they are produced. To increase or decrease money incomes without at the same time increasing or decreasing the volume of output in the various lines of production, must of necessity result in, be accompanied or preceded by, a like proportionate change in the general level of pricesby a like proportionate change in the money-cost of living.

Every dollar of money income, no matter by whom received, is spent in the purchase of goods and services. The goods purchased are either consumption goods, i.e., goods that directly satisfy human wants; or pro- duction goods, i.e., machines, tools, buildings, etc., used in further production. The exception to this in the form of money hoarding is negligible; indeed, it merely alters the division of the product of industrial society slightly at the time of hoarding and at the time of bringing the money out of the hoard. The fact that not quite all of the money income received during a given period of time-given week, given month, given year-is spent in that period but that there is a lapping over into the next period, is of negligible consequence because of the drag from the preceding period.

That the income that is "saved" by depositing it in savings banks and other institutions is also spent becomes evident if we follow it to its ultimate disposition. For these institutions "invest" it, i.e., buy national, state or municipal bonds or the securities of railroads and industrial corporations. The ultimate receivers of the saved funds spend them either on consumption goods or in the purchase of machinery, tools, erection of buildings, bridges, street paving, road building and so on. Whether spent directly or "saved," every dollar of money income is spent in the purchase of goods or services.

All goods that are produced are sold. The spoilage of strawberries over the week-end and of other perishable goods may be neglected for the purpose of this analysis. Indeed, any spoilage, any failure to sell goods once produced, represents to some extent a defeat of the ultimate purpose of our industrial structure and activity, which is to provide the greatest attainable abundance of all goods in the proportions in which they are needed for the satisfaction of the wants of all people.

It follows that the sum total of money incomes received during a given period, particularly if that period be a 
year, is exchanged against the sum total of goods produced and personal services rendered during a corresponding period. We say "corresponding" rather than "same" period for two reasons. First, we have already shown that a large portion of our current weekly or monthly money incomes are spent, not for the products on which we worked during the week or month in which we earned the incomes but upon the products of our earlier endeavors-earlier by a few weeks, possibly months: the purpose of this week's productive activity is to provide for our wants of next month or next winter: Second, there is a little elasticity in the relationship. In the case of those goods whose production is seasonal, stocks accumulate during the production period and are depleted during the remainder of the year, or consuming season. Also, the stock of consumption goods may be built up during a given year or other comparable period of time; but there is a practical limit to the extent to which this can be done because of the expensiveness of carrying large stocks. In foods and other materials produced by the extractive industries, stocks are accumulated only to the point required as a margin of safety against lean years (and not always to that point) and then simply maintained. Again, in the case of savings, time is consumed in their transition through the financial institutions to the organizations that ultimately spend the funds; furthermore, a large part of this spending waits upon the appearance of its objects of expenditure which are produced to order. Therefore, we say "corresponding" period.

\section{Money, Prices and Goods and Services}

This relationship establishes a close correspondence between three systems of facts; viz.: (1) the volumes of output of the various kinds of commodities and services; (2) the aggregate volume of the flow of money income and its division among persons with their varieties of wants; (3) the prices of commodities and the general level of prices.

Keep the volume of money income steady and increase the rates of production of the various kinds of goods, and two things happen. First, the money costs of production of these various kinds of goods are reduced; for what are money incomes to the recipients, are money outgoes to the firms and corporations paying them. Consequently, these goods can be sold at correspondingly lower prices and still leave the business as profitable as before.

On the purchasers' side, they have no more money per week to spend in the purchase of all these goods than previously at the smaller rates of production. Consequently, if a greater volume of goods is to be sold they must be sold at lower prices. And competition among rival producers, no one of whom wants unsold goods left on his hands or wants to close his plant and let the still normally profitable business go to his rivals, as well as competition among products under the aforesaid condition of reduced costs, will bring the prices down.

In this case, there is an increase in social well-being. With the same money incomes the masses of people are able to supply themselves in greater abundance. Such being the case there may be a change in the proportion between direct consumption and "savings," in the direction either of a greater proportion of saving or of a greater proportion of immediate consumption, according to what seems the more worth while to the mass of the people, each person deciding for him- 
self. Nevertheless there will be an absolute increase in both consumption and saving. Because of the change in proportion, however, the prices of production goods and of consumption goods may not be reduced proportionately, and, in fact, because of a shifting of industry, the total volumes of the two classes of goods will not be permanently increased in the same proportion.

If the volume of money incomes is maintained constant and the rates of production of the various commodities are lowered, the reverse situation is produced. Money costs per unit of output are increased and the goods cannot be sold so profitably, perhaps not profitably at all, at the old prices. On the other hand, purchasers having the same amount of money per week as before and competing for a smaller available quantity of goods, will bid up the prices. And the producers, because of their increased unit-costs, will ask higher prices and be able to get them. Thus, even if money incomes are maintained constant, decreased production means decreased well-being of the recipients of income - of the mass of the people. What probably happens in this unfortunate situation is that the prices of consumption goods, particularly of the necessities of life, rise more than do the prices of production goods, that there is a change of proportion between consuming and saving, saving being reduced under the pressure, and that the expansion of industrial facilities is checked. If the stress is great enough, existing facilities may not even be maintained; railroads, industrial plants and so on are let run down, producing a condition for which industrial society later must pay.

If the rates of production are kept constant and money incomes generally are increased, two things happen.
First, since from the viewpoint of the producing firms these money incomes are production costs, these production costs per unit of product are thereby increased, the products cannot be sold so profitably at the old prices and higher prices will be asked. And higher prices will be paid. For, second, the whole mass of purchasers, finding themselves with more money perweek, there being, in fact, no more goods available for purchase with this money, will be able to pay the higher prices for such goods as are available. Competition among this great mass of rival purchasers, each of whom will insist upon getting at least as much as he was getting before, will cause the prices to rise until the whole increased volume of money income is absorbed in the higher prices.

Thus mere increase in the money income of the mass of the people does not cause increased well-being. In this case, since the various kinds of goods are produced not only at the same rates of flow but in the same proportions as before-in other words, since the sum total of economic wellbeing is not changed-all prices will tend to rise in the same proportion.

In like manner, if production rates are maintained constant and money incomes lowered, prices must come down proportionately. On the purchasers' side, there is less money with which to buy this same volume of goods and there must be a reduction in prices if all the goods are to be sold. On the other side, the money costs of production are lowered so that the producers can sell at proportionately reduced prices and still leave the same proportionate margin of profit; and competition among rival producers no one of whom wants goods left on his hands or an idle plant when it could still be run profitably, will force the prices down. 
Therefore, the economic well-being of the mass of the people can no more be bettered or injured by a general proportionate increase or decrease of money incomes unaccompanied by a like change in the general productivity of industries, than can a man lift himself over a stone wall by pulling on his boot-straps. Indeed the general level of money incomes is nothing and the general productivity of industries is everything in the economic well-being of the great mass of people.

However, it may be claimed that, while this is true of the sum total of money incomes, wage incomes constitute only a part, not the whole, of this sum total and that a general wage and salary increase will benefit the recipients because it will increase the wage earners' proportion of this sum total; that therefore the wage and salary class will get more, and the profit taking class will have less.

This reasoning would be valid if the increase in the sum total of money incomes were of necessity limited to the wage and salary increases granted -if the wishes, beliefs and motives of land owners and business men, whether farmers, manufacturers, transporters or distributors, were of no weight in the matter. But they are of the same proportionate weight as before and the increase in the sum total of money incomes is not limited to the wage and salary increases. On the contrary, the landowners have the power to advance money rent rates to the point at which they can get the same proportion of the total social product as before; business men have the power to advance their prices so as not only to cover the advance in production costs, inclusive of land and other rents, but to restore their margin of profit to the same proportion as before. Not until the mass of workers simultaneously find means of changing the motives, convictions and desires of landlords and of business men so that competition among their weakened wills will compel them in a given situation to be content with less rent and a smaller margin of profit than is now the case, will workpeople be able, through a general proportionate advance in their money incomes, to increase their proportion of the total social product. When they attain this power, they can increase their proportion without any advance in their wage- and salary-rates.

It is true, indeed, that if the wage earners of one particular business establishment obtain a general increase in week-wage rates without giving a corresponding increase in production and without there being a corresponding adjustment of the wage-rates and production costs among that house's competitors, then the increased wage incomes may be at the expense of that firm's profits. For while its unit-costs are increased thereby, this firm cannot recoup itself by raising the price of its commodity. Competition of rival producers, who are not restricted by like increased costs, will prevent.

However, if all competing firms are subjected to a proportionate wage increase, they are left on the same competitive footing as before the wage increase and can, and will, increase their prices not only to the extent of the increase in unit wage-cost but to the extent of a margin of profit on this cost in addition. In this case, the manufacturers may not be able to maintain the same proportionate margin of profit, because, with the advance in the prices of this commodity, the mass of the general public - the people in the other industries-who have not had their money incomes increased, cannot buy as much of this commodity and, at the same time, buy as much of everything else as before. 
They must reduce their purchases of something. Probably they will reduce somewhat their purchases of many things; however, the commodity whose purchases are most reduced is the commodity whose price is advanced. The more necessary is the commodity, the less is the effect on its purchases; the less it is necessary, the greater is the effect. So that unless those industrial workers who get the increase spend the whole of it, and even more, in the purchase of the very commodity they are producing (an act that would leave them worse off than before) their increased money income would to a certain extent come out of their employers' profits.

However, reduced volume of sales means reduced production and reduced employment. Advancing the price of one commodity out of its former relationship to the prices of other commodities, reduces the effective demand for it and creates idleness and unemployment within that industry until a transfer of production facilities and working force to other industries can accommodate the remaining capacity to the reduced demand. During this period of adjustment, unemployment will offset, to a considerable extent, the increase in wage-rates, perhaps even reduce the total annual money income of this group. There is such a thing as a group of persons' overreaching themselves.

However if the wage increase be general, not to one industry but to all industries, then the remainder of the buying public also would have proportionately more money to spend, could sustain the higher prices and not only would the increased cost of the product of the industry in question all be passed on in higher prices, but the higher unit-costs of all other commodities would also be passed on in higher prices. Furthermore, materials would cost more; machinery and tools would cost more; for these are themselves products. And when the process of adjustment was complete, we should have passed to a general higher price level in which money profits would share proportionately.

While workers cannot increase their proportionate share of the total product of industrial society by means of a general proportionate increase in wage- and salary-rates, unless the volume of production is also increased, neither can employers increase their share of this product, or reduce the workers' share by a general proportionate decrease in wage- and salaryrates. For, as we have already seen, unless production is reduced, prices must come down in like proportion and a 20 per cent less money income will buy the same quantity of commodities as before. The essential thing is that production be maintained undiminished.

Likewise, if industry has come to equilibrium at a given system of rates of production, income rates and prices, there cannot be an arbitrary reduction in prices not justified by increased productivity and reduced production costs without a corresponding reduction of money incomes inclusive of wage- and salary-rates, i.e. unless production stops. A reduction in prices without correspondingly increased productivity of industry means reduced gross money income of business men. If the expenses of production are not decreased, this means not only that profits are reduced both absolutely and relatively but that they may even be converted into losses. The latter condition cannot last long. Nor can a relative reduction in profits endure long unless the normal mental attitudes of business men have altered in that direction. Pressure will be put on workers through demands, argument and un- 
employment until wage- and salaryrates have undergone a like proportionate change.

While wages cannot entrench on profits by means of general proportionate wage-rate advances and profits cannot entrench upon wages by means of general proportionate decreases in wage-rates, nevertheless it $i$ s possible for one person to benefit at the expense of the mass; for one group of industrial workers to benefit at the expense of the others; for clothing cutters, for clothing workers as a whole, for glass-blowers or railroad workers either to benefit at the expense of the mass by means of a wagerate increase or to be injured by a wage-rate decrease. If the total money income of society is $\$ 100,000$,000,000 a year, of which my portion is $\$ 10,000$, then my annual purchasing power over the product of industrial society is $10,000 / 100,000,000,000$, or one ten-millionth part of the total, the exact meaning of which depends upon the proportions in which I value the various commodities as compared with the proportions in which the remainder of the whole competing mass of purchasers values them. Double my income, keeping that of everybody else unchanged, and my purchasing power becomes $20,000 / 100,000,000,000$, or $2 / 10,000,000$ part of the total; I have practically doubled my purchasing power at a slight loss to every other member of society. Cut my income in half without changing that of anybody else, and my purchasing power becomes $5,000 / 99,999,995,000$, or $1 / 19,999,999$ part of the total; it has been cut practically in half to the benefit of every other member of society.

The foregoing takes no account of the effect upon production that may be caused by doubling or halving my income. Likewise, if the original hundred billions includes, say, $\$ 416$,-
000,000 earned by 200,000 clothing workers, and they can get this increased by 100 millions without there being any change in the money incomes of anyone else, their combined purchasing power becomes increased thereby from $416 / 100,000$ to $516 / 100$,000 part of the total product of industrial society, an increase of nearly 24 per cent in the purchasing power of this small group at an expense of slightly less than one-tenth of one per cent to every other member of industrial society. A like proportionate advance to $3,000,000$ workers in the building trades would come at the expense of fifteen times as much or $1 \frac{1}{2}$ per cent, to the remainder of industrial society.

We say "expense" because if the wage increase is not accompanied by a corresponding increase in the productivity of these workers, the more purchasing power they get the less is left for other people. We do not mean, however, that such increases may not be justified - that they may not merely correct a relative under-remuneration of such groups of workers as compared with the great mass of other workers, as probably was true of some of the wage increases obtained by the formerly sweated clothing workers.

Therefore, while it is not possible to better the standard of living of the whole mass of industrial workers by a general proportionate increase in money wage-rates, or to lower their standards by a general proportionate rate decrease, and since, therefore, the cost of living as a basis of wage-rate adjustment is impotent for the mass, unsound in principle and vicious in its operation, it is possible to give preference to one class of industrial workers or to a few classes as against the others by increasing their wagerates and holding those of the others down. 
This is all that wage adjustments that are made on the basis of living cost do; whether the basis of adjustment is some assumed "living wage" or merely relative changes in the cost of living. They merely give a preference to the workers affected as against the remainder of the mass of people.

\section{Relations Between Wage-Rates of Various Occupations the IMPORTANT Matter}

It may well be that in certain cases such preference is just-that, as a matter of fact, these industrial workers were underpaid as compared with the general mass of industrial workers and that what appears to be a preference merely adjusts the wage-rates of these workers to proper relation to the general system of wage-rates. No doubt clothing workers were at one time so underpaid - the time when they received mere pittances under the piece-work sweatshop system and perhaps even in more recent times. It is not unlikely that department store sales girls have been so relatively underpaid. However, the question in such cases is not what is the relation of the money wages to a living wage (such an undefined expression!), not what is the relation between the change in wage-rates and the change in the cost of living. The real question is this: What is the relation between the wage-rates of the various occupations in this industry to the general mass of wage-rates? Are these workers underpaid, overpaid or properly paid for the work that they do as compared with the general system of wagerates for the work that their recipients do?

Answer this question correctly and adjust rates accordingly, and distributive justice as between various groups of industrial workers will be accomplished. Answer it correctly and ad- just accordingly, and the purpose of "minimum wage" legislation will be accomplished and more than accomplished, if the affected workers produce a minimum of subsistence or more. Answer this question correctly and adjust accordingly, and we need not inquire how large a man's family ought to be, how many pairs of shoes, how many pounds of potatoes, of beef, of sugar and the like, he needs. As if industry were carried on primarily for the benefit of landowners or business men and they were to get all the product of industry in excess of what the members of the labor factor need barely to sustain life or in excess of some uniform standard of living that some self-constituted body may fix upon! As if there were or could be a uniform standard of living! As if an attentive, ambitious, highly productive tool maker should be deprived of a part of his product for the benefit either of his employer or of his unambitious, inattentive, relatively unproductive brother tool maker! As if highly trained, highly skilled tool makers should receive no more pay and live no better than the untrained, unskilled worker just entering industry! As if the structural steel worker who risks his life every minute should receive no greater remuneration and live no better than the farm worker who works in comparative safety! As if the coal miner who spends a large part of his life in damp dusty darkness, or the drop forger who sweats before fierce furnace fires should receive no greater remuneration and live no better than a sleeve maker, sitting comfortably before a sewing machine in a well-lighted sanitary factory! We have already shown that a standard of living is a personal thing, effective only as it restrains and stimulates and governs individual conduct. There is not one standard of living among the 
workpeople of the world but millions of them.

When a worker feels the pressure of the cost of living (and no matter how large money incomes may be, workers will continue to feel the pressure of the cost of living so long as the productiveness of industry is little more than sufficient to meet the primary needs of the people, so long as the increase of population keeps pace with the accumulation of capital and the advance of science and the industrial arts), he naturally is also pressed to increase his own income. Any group of workers so pressed naturally reacts in the same way and, if organized, makes its demands. This should raise the question of whether this group is properly paid for what it does as compared with the remuneration of other groups for what they do.

\section{Elements Determining Normal Relations Among Wage-Rates}

The answer, however, must be sought, not in comparing their wagerates with the cost of living at any assumed standard, but in a comparison of the wage-rates of the group in question with the mass of other wagerates, and in an analysis of the various jobs, operations or occupations with reference to those influences or factors that, at any given system of rates, affect the relative supply of workers in these various jobs, operations or occupations. Here we hark back to Adam Smith. Let us consider the production of the various commodities in certain given volumes. With a given technique of production there is a certain system of operations, on each of which is needed, at certain given rates of effectiveness or productivity, a certain number of workers. There is a certain given population potentially available for distribution among these operations. Will workers be available for these various operations in the quantities and proportions needed? That depends upon the relative rates of remuneration. Some operations require quick, keen intelligence, some do not; some require a long time in which to come up to full proficiency, some can be mastered in a few days; some require a certain background of general knowledge and education, some can be well performed by gross illiterates; some require great strength, some require very little; some require fine precision and close attention, some require much less accuracy and put no strain on the attention; some entail large responsibility because of the loss or damage that can easily result from carelessness, some entail little responsibility; some subject the workers to great discomfort, some are comfortable and agreeable; some subject the workers to health deterioration, others are perfectly healthful; some are dangerous, some are safe; some subject the workers to long seasons of idleness, some offer opportunity for working as continuously as the worker himself is willing to work. And so on. Between the extremes there are all gradations.

Each of these aspects of an operation or occupation constitutes a degree of restraint that prevents the free flow of workers from one to another, or a repelling influence or, perhaps, an attracting influence. At a given system of relative wage-rates the industrial population will, in the course of time, distribute itself among these occupations and operations in certain proportions. If these are the proportions in which they are needed, well and good. At any given arbitrarily chosen system of wage-rates, however, it is altogether probable that the supply of labor would be short of the demand in some operations and in excess of the demand in others. Competition will tend to raise wage- 
rates in the one case and lower them in the other. Competition will tend to adjust relative wage-rates so that the demand for labor will equal the supply in each operation. And the final test of the relative accuracy of any system of wage-rates is their relative power of attracting and holding workers in the proportions in which they are wanted.

The proportions in which workers are needed in the various operations and occupations are undergoing continuous change, however, owing to the coming of new employers, the disappearance of old, the expansion of some establishments, the contraction of others, the appearance of new commodities or improved designs of old and the fall of others from favor, the change of fashions and the change of consumption habits. Industry is in a state of continuous flux: equilibrium is never attained. Because of the restraints spoken of above, the working population cannot adjust itself instantaneously to these changes. Hence, even if demand equalled supply all along the line at one time, it would be out of adjustment at another; there would be a relative deficiency of workers in some lines, a relative surplus in others. In the occupations with relative surplus force, market wage-rates may temporarily be depressed below the normals, the rates that will normally be approximated, a condition that leads to high labor turnover; while in others, the temporary scarcity and resulting abnormally high rates may attract more people relatively than can normally be accommodated, a condition that later will contribute to abnormally low rates and high labor turnover there.

These mutually disadvantageous conditions could be avoided if we had some means of determining the normals and could pass directly to them. We know of no way to accomplish or even approximate these except by conscious analysis of each operation with reference to the degree to which it involves each of the above enumerated influences and any other which later analysis and more mature consideration may find pertinent, rating all operations with reference to each influence, getting for each operation a rating factor for each influence, and combining all the factors for any given operation into a single relative rating factor. Thus a certain operation might be rated unity on the danger factors; 1.5 , on strength; unity, on precision and attention; 1.25, on discomfort; 1.3 , on intermittency of employment and so on resulting in a combined relative rating factor of $1 \times 1.5 \times 1 \times 1.25 \times 1.3 \times$ and so on, or 2.44 for the five component factors given. For another operation, the series of factors might be $1.05 \times 1 \times$ $1.2 \times 1.1 \times 1.15$ and so on, or 1.59 for the same five components. Were these the only components or were all the other components unity for each of these two operations, then the relative wage-rates for equal degrees of technical effectiveness would be as 2.44 to 1.59 ; if the wage-rate for one was 48.8 cents per hour, that of the other would be 31.8 cents.

Such relative rating would be no easy process. It involves painstaking analysis of each operation. It involves invention and definition of units of discomfort, of exposure to injury, of exposure to ill health, of exposure to unemployment, of strength, and so on; it involves a relative valuation of these influences one to another. It involves much that has never been undertaken except to a small extent recently in psychological laboratories. It is not something that can be completed this year. It is not a basis of wage-rate adjustment that is available in the present situation. Yet it is something the results of which are approximated by 
every concern that adopts a successful wage scale at which to hire, and by which to advance, workers in the occupations and operations with which it is concerned. And it is something that may be available in the next situation, like the present one, if we commence and carry on the researches through which we must go to reach the goal.

\section{Performance Standards Necessary for Effective Relative Rating}

Such a relative rating must refer to a definite amount of work or rather a definite degree of effectiveness in each operation or occupation. We cannot effectively rate handkerchief hemstitching and coil winding as mere names of operations; we must rate a definite degree of effectiveness of performance in these two operations. If stitching rolled edge hems on 100 dozen 9 -inch by 9 -inch handkerchiefs in 7.8 hours with 24 stitches per inch on a machine speeded at not less than 2,825 stitches per minute is a fair rate of performance, and if winding 390 Ford ignition coils in 12.3 hours under similarly specified conditions is a fair rate of performance, then in relatively rating these two operations they should be rated at these rates of performance. This establishes relative ratings at certain standards of performance. Then, within the operation, the individual worker may be remunerated according to his actual performance; if his rate of performance is 90 per cent of the standard his remuneration can be fixed at 90 per cent of the standard rate for the operation; if 110 per cent, it can be fixed at 110 per cent of the standard rate.

Obviously this involves the careful analysis and study of work and the careful determination of fair standards of performance. Furthermore, to be fairly applied, it involves a kind of management that effectively main- tains the conditions on which the performance standards are based.

\section{Relative Rating a Force Making FOR Stability}

Such a relative rating would operate to stabilize the rates of remuneration for the various classes or grades of operations and occupations. Stabilizing these automatically stabilizes the prices of commodities except in so far as natural phenomena, such as variations of weather conditions in agricultural and animal husbandry, intervene to vary the productiveness of industry, and except in so far as progress in the industrial arts makes industry more productive and lowers the price.

We submit that such stabilization is highly desirable. We submit that such instability as that we have experienced in the last few years is demoralizing and distressing.

\section{Relative Rating Not a Bar to INDIVIDUAL ADVANCEMENT}

Does stabilizing rates of remuneration mean that the individual.worker will strike a level of earning power and go no further during the remainder of his life? By no means. The individual can still progress as rapidly and as far, on the average, as is now possible. The ranks of industrial workers, whether managers or workers at the bench, are continuously being depleted by retirement, disability and death; they are continuously being recruited by others who enter industrial work, mostly by the young persons who come up to the age of self-support. Naturally as persons drop out of the operations of higher skill and value, their places will be taken by advancement from the operations of less skill. Naturally the person who is just entering industry is inexperienced, unskilled and must go into relatively less 
skilled and low valued work. Hence the normal course of development of the individual is gradual advancement from work of relatively low value to work of relatively high value.

The thing for workers to insist upon is that these opportunities for advancement to work of higher value, including advancement to all grades of executive work, be offered on the basis of proved merit rather than upon the basis of either favoritism or indefinite impression.

\section{Practical Procedure to Start Relative Rating at Once}

Is it necessary to wait until all this analysis is completed in order to get a working basis for relative rating? We think not. The Franklin Motor Works used the rates for the various occupations that prevailed in 1905 as the basis of their relative rating. The rates of that year were chosen because those seemed to be the rates most satisfactory to workers as evidenced by the low labor turnover rates of that year. From the viewpoint of workers this is probably the best index to the relative satisfactoriness of rates. If the rates of turnover are the same in the various occupations and operations or if they increase as we go downward from the highest valued operations, but increase gradually (for we hope that those in lower valued operations are less contented than those in the higher valued and seek to progress), this fact may be taken as indicating fair satisfactoriness of such rates.

Such a basis gives us a start. Then, if workers and employers accept the principle of relative rating and are willing to coöperate in putting it into operation, the work of analysis, rating, testing and correcting can start and proceed until in the course of time the data for more satisfactory relative rating accumulate and become practically available.

\section{Wage Adjustment}

\section{By SANFord E. Thompson}

The Thompson and Lichtner Company, Consulting Engineers in Industrial Management and Construction

$\mathrm{T}$

1HE problem of wage adjustment must be considered from three angles and each of these three requires independent treatment:

1. General wage levels

2. Relative wages

3. Individual earnings

Wage levels, meaning the average earnings of large groups of workers, are governed not merely by laws of supply and demand and all of the variables incident thereto, but also by fluctuations in money values that are produced largely by causes outside the range of wage action.

Relative wages may be considered as the relative levels of earnings in different operations in the same establishment and, in a broader sense, the relative levels in different localities and in different industries.

Finally, individual earnings should be determined by individual production. In these, more and more account is being taken-although this is often excluded in economic theories-of the ability of the particular shop or the particular industry to pay through natural causes, or the skill of the managerial organization to obtain with the coöperation of the worker, exceptional results.

At the present time it is the general wage level that is uppermost in the treatment of the problem of wages. 